\title{
On metaknowledge in the pigeon: An organism's knowledge about its own behavior
}

\author{
CHARLES P. SHIMP \\ University of Utah, Salt Lake City, Utah
}

\begin{abstract}
In two experiments, pigeons pecked side keys in a discrete-trials setting in which shorter and longer runs of successive pecks on the left key before a switch to the right key occasionally produced, after a brief retention interval, a short-term memory probe for the most recent run length. In Experiment 1, a probe involved red and green side keys. A peck to a green (red) key was reinforced if the previous run length was shorter (longer). The dependent variable was the probability of a peck to the correct color. In Experiment 2, a probe involved an autoshaping procedure in which a response-noncontingent reinforcer was delivered after a 5-sec presentation of a green (red) center key if the previous run had been a shorter (longer) one. A reinforcer was not delivered when a red key followed a shorter pattern or a green key followed a longer pattern. The production of runs conformed to many previous molecular data on the way the local temporal patterning of behavior adapts to, that is, displays knowledge of, a reinforcement contingency. The probe results showed that a pigeon can report which of two run lengths it recently has emitted. Thus, a pigeon can, in a sense, describe its own adaptive behavior. Since the adaptive behavioral patterning on the center key may be said to represent knowledge, and since the probe behavior is a self-characterization or self-report by the organism about this knowledge, the probe behavior may be said to represent knowledge about knowledge, or metaknowledge. The data extend previous work on metaknowledge in the pigeon to a third type of adaptive temporal pattern of behavior, that is, run length (instead of response duration and interresponse time), and provide a second type of probe procedure, that is, autoshaping, by means of which a nonverbal organism can be asked what it knows about what it is doing to adapt to an environmental contingency.
\end{abstract}

The relation between performance and self-reports of that performance is once again assuming a major theoretical role in human cognitive psychology (Brown, 1975; Gazzaniga, 1970; Jacoby \& Dallas, 1981; Nisbett \& Wilson, 1977). This research relies heavily on human subjects' verbal self-reports. Related experiments, however, can also be conducted with nonverbal animals (Nelson, 1974; Shimp, 1981; Ziriax \& Silberberg, 1978). For example, Shimp (1981) arranged a setting in which a pigeon produced a behavior stream consisting mostly of shorter or longer interresponse times on a center key. This behavior revealed a rather precise adaptation to the reinforcement contingency for center-key pecks. Such adaptation constitutes, in a sense, a kind of knowledge on the part of the subject about what the centerkey reinforcement contingency is. In addition, symbolic matching-to-sample trials were occasionally arranged on colored side keys: a response to a particular colored side key was reinforced if the preced-

This research was supported in part by NIMH Grant 16928 . The author would like to thank Stephen J. Hutton for his expert help with the conduct of this research. The author's mailing address is: Department of Psychology, University of Utah, Salt Lake City, Utah 84112. ing pattern on the center key had been of the appropriate duration. For example, a peck to a green side key was reinforced if the preceding pattern on the center key belonged to the shorter category. A peck to a red side key was reinforced if the preceding pattern had been a longer one. This procedure permits one to look at the relation between two different behaviors that may be said to correspond to knowledge and metaknowledge: the behavior on the center key displays the subject's knowledge about what it has to do to collect reinforcers, and the behavior on the side keys displays the subject's self-report or self-characterization of this knowledge and, in this sense, displays metaknowledge about what it is doing on the center key.

Experiments that have used similar procedures with infrahumans have established baseline behaviors involving response duration (Ziriax \& Silberberg, 1978) and interresponse time (Nelson, 1974; Shimp, 1981). The present experiment was designed to extend the study of metaknowledge in infrahumans to a third, somewhat more elaborate, class of behavioral pattern: the lengths of runs of successive responses on one of two side keys in a discrete-trials setting. This kind of contingency has been used in isolation on previous occasions, and, therefore, how 
behavior adapts to it is known already in some detail (Shimp, 1982, in press). Here, what an organism that is displaying adaptation to this contingency can report about what it is doing is asked in two different ways. In Experiment 1, the question is asked with the same probe procedure used by Nelson (1974), Shimp (1981), and Ziriax and Silberberg (1978). In Experiment 2, the question is asked with an autoshaping procedure adapted from work by Wasserman and others on short-term memory (Nelson \& Wasserman, 1978; Wasserman, Nelson, \& Larew, 1980).

\section{EXPERIMENT 1}

\section{Method}

\section{Subjects}

Nine White Carneaux pigeons were given, after daily sessions, food sufficient to maintain weights equal to $80 \%$ of free-feeding weights, plus or minus $10 \mathrm{~g}$. Birds 2,3 , and 4 had served previously in delayed matching-to-sample experiments using food-hopper durations as sample stimuli. Birds $1,5,6,7,8$, and 9 had served previously in experiments involving the reinforcement of various run lengths, as in the baseline behavior of the present experiment (see Shimp, 1982, in press, for details). A 12-h/12-h light-dark cycle was maintained in the colony room, and water and grit were always available in the home cages.

\section{Apparatus}

Five standard three-key Lehigh Valley Electronics pigeon chambers were interfaced to a Digital Equipment Corporation PDP 8/e computer, which arranged all experimental contingencies and recorded the data. All three keys, which required a minimum force of approximately .1 to $.2 \mathrm{~N}$ to operate, were used. White noise and fans in the chambers helped to mask extraneous sounds.

\section{Procedure}

The procedure consisted of two major components, a procedure to establish a baseline behavior stream of temporal patterns, and a probe procedure to ask the subjects what they knew of the pattern that they had most recently completed.

Pattern-shaping procedure. This component of the procedure involved a discrete-trials arrangement in which access to the probe component depended on the occurrence of a peck on the right key after a suitable number of pecks on the left key. The details were as follows.

Discrete-trials contingency. Each trial began with the illumination of the white left and right keys and of the houselight. A peck on the left key turned off all the lights and initiated an intertrial interval, which was always $.25 \mathrm{sec}$ in the conditions for which data are reported here (but see Table 1). Such a response increased the length of the current run of left-key pecks. A response on the right key also turned off all the lights and then either initiated the same intertrial interval or initiated reinforcement, provided a variable interval had elapsed and the computer was looking for the particular run length just terminated by the changeover to the right key. A peck to any key during the intertrial interval restarted the intertrial interval.

Variable-interval contingency. A random-interval schedule was used. Once every second, the computer calculated a quasi-random number that, when compared with .5 , gave a decision to arrange or not to arrange a probe. Thus, this aspect of the schedule was a random-interval 2-sec schedule. The variable-interval (VI) contingency arranged reinforcers at a rate sufficiently high that, for all practical purposes, the schedule may be viewed as having been a continuous reinforcement schedule: much of the time, a reinforcer was arranged for one or the other pattern. Once arranged, a probe remained so until administered. The 1-sec timer ran only during the intertrial interval to discourage long pauses when the keylights were on.

Response-pattern contingency. When a probe was arranged by the random-interval contingency, it was probabilistically allocated to one of two response patterns, a shorter and a longer run of left-key pecks. Once a probe was arranged, the random-interval timer was stopped. This feature permitted the experimenter to control the way reinforcers were distributed between the two reinforced patterns (Shimp, 1966): as a result of this procedure, probes were delivered equally often after shorter and longer patterns. A pigeon's frequency distribution of shorter and longer patterns had no effect on the relative-frequency of probes after shorter and longer patterns. The two patterns were the same throughout the experiment: the shorter and longer patterns consisted of runs of exactly two and five left-key pecks, respectively.

Probe procedure. This component of the procedure was a short-term memory probe that asked the animal about its preceding pattern of behavior. In general, this procedure worked as follows. A keypeck gave access to a retention interval, provided that a random interval had timed out, that the peck was a changeover to the key on the right, and that the length of the terminated run was that chosen by the response-pattern contingency (see above). The red and green side keys appeared after the termination of the retention interval. A bird was required to peck one color if the previous run had been the shorter pattern and to peck the other color if the previous run had been the longer pattern. The details of this procedure are described below.

Each probe was initiated by a right-key changeover peck, and it therefore was feared that a right-key bias might emerge in the test phase of a trial. Therefore, the changeover peck that initiated a probe first darkened both side keys and turned on a white, center key. The first peck on the lighted center key initiated a retention interval. Thus, the probe effectively began with a bird positioned approximately midway between the two side keys. Note that the latency to peck the center key added a small amount of time to the nominal retention interval.

Retention interval. During the retention interval, the experimental chamber was dark and a peck on any key had no programmed consequences. Table 1 shows the retention interval for every condition (range $=.1$ to $6 \mathrm{sec}$ ).

Test phase. When the retention interval timed out, red and green appeared on the side keys, with the position of a particular color varying randomly from one probe to another. A peck to the green key turned off the side keys and initiated reinforcement when the most recent pattern had been a shorter one, and a peck to the red key initiated reinforcement when the pattern had been a longer one. After reinforcement, the intertrial interval was started. A peck to the incorrect color initiated a correction procedure.

Table 1

Experimental Conditions

\begin{tabular}{cccc}
\hline $\begin{array}{c}\text { Condition } \\
\text { Number }\end{array}$ & $\begin{array}{c}\text { Birds in the } \\
\text { Condition }\end{array}$ & $\begin{array}{c}\text { Number } \\
\text { of Days }\end{array}$ & $\begin{array}{c}\text { Retention } \\
\text { Interval }\end{array}$ \\
\hline 1 & $1-9$ & 15 & .1 \\
2 & $1-4$ & 42 & 2.0 \\
3 & $1-4$ & 15 & .1 \\
3 & $5-9$ & 15 & 2.0 \\
4 & $5-9$ & 15 & 6.0 \\
5 & $5-9$ & 15 & .1 \\
\hline
\end{tabular}

Note-Retention intervals are given in seconds. Before the conditions reported here, and between Conditions 1 and 2, 2 and 3 , and 3 and 4, were other conditions in which various unsuccessful attempts were made to lengthen the intertrial interval beyond 2 sec or longer. 
Correction procedure. A choice of the incorrect key was followed by a 5-sec correction interval, during which the key lights were off but the houselight was on. After the 5 sec had elapsed, the side keys appeared again, with the same assignment of colors to positions. This correction procedure continued to recycle until a correct response produced reinforcement and ended the probe. This procedure, coupled with probes that were delivered equally often after shorter and longer patterns, ensured that reinforcement was delivered equally often after pecks to a particular color and position.

Experimental conditions. Table 1 shows how the retention interval was varied over conditions. The nine birds were run in two groups, and, as Table 1 shows, the two groups received somewhat different series of conditions.

Miscellaneous detalls. Reinforcement consisted of $1.5 \mathrm{sec}$ of access to the same mixed grain that provided a subject's daily diet. During reinforcement, all lights in the chamber were off except for one directly over the food hopper. The duration of each session was $45 \mathrm{~min}$, except for the 60-min duration for Birds 5-9 in Condition 2. These values depended partly on the need to keep a bird's weight within the specified range and partly on the scheduling of other experiments in the laboratory. Each experimental condition lasted 15 days, which sufficed to reach a criterion of stability based on an examination of the number of obtained reinforcers, the distribution of run lengths, and the probability of a correct response in probes.

\section{Pretraining}

Pretraining, after an initial period not involving probes and during which only runs of lengths 2 and 5 on the left key were shaped, was slightly different for the two groups of birds. For Birds 1 to 4, probes were introduced after 84 days of such training, and for Birds 5 to 9, probes were introduced after 59 days. Subsequently, a right-key bias began to emerge for several birds during the probes. In a successful effort to reduce this key bias, all birds were given 1 day of training with all probes following long runs and with the correct color, red, on the left key. After this 1 day with an altered contingency, the experiment, as described in Table 1, began. Pretraining lasted a total of 99 days for Birds 1 to 4 and 73 days for Birds 5 to 9.

\section{Summary and Example of the Procedure}

A pigeon successively pecked left and right keys in a discretetrials setting in a manner that produced a number of shorter and longer runs of left-key pecks. Occasionally, this procedure was interrupted, and, after a retention interval, a pigeon was asked whether its preceding run had been a shorter or a longer one: it was provided red and green keys, and a peck at the former was reinforced if the preceding pattern had been a longer one and a peck at the latter was reinforced if the preceding pattern had been a shorter one.

The following example of moment-by-moment events may help a reader to understand the procedure. After a short intertrial interval, during which the chamber is darkened, a pigeon confronts two lighted left and right keys. Let us suppose that the bird now pecks the left key. Such a response turns off the lights, starts the next intertrial interval, and increments a counter that keeps track of how many successive pecks at the lighted left key have intervened since the most recent peck at the key on the right. The counter, that is, updates the length of the current run of left-key pecks. Let us suppose that this left-key peck is the fourth straight left-key peck since the last right-key peck. After the intertrial interval times out, the bird again confronts the two lighted left and right keys. Let us again suppose the bird pecks the left key and initiates the next intertrial interval. Now the length of the current run of left-key pecks is five. After this intertrial interval, both keys again are lighted. If the computer has arranged a probe for a run of length 5 , and if the VI timer has arranged a probe, a right-key peck, since it will terminate a run of length 5 , will initiate a probe. A probe begins with the illumination of the center key, a peck on which turns on red and green side keys, with the position of a color selected randomly. A peck at the green key would initiate reinforcement.

This procedure becomes clearer if one bears in mind the implications of earlier work on temporally defined units of analysis. Despite the fact that, to all outward appearances, this procedure involves a choice between two alternatives (the left and right keys), the two alternatives are in fact not the responses themselves, but the patterns of side-key responses. The choice is between a shorter pattern with a run length of 2 and a longer pattern with a run length of 5 . The justification of this view is not so much simply that the delivery of a reinforcer explicitly depends on these patterns as it is that the relation between behavior and reinforcement in this and in related experiments makes sense in terms of units of analysis that are patterns but little or no sense in terms of units that are individual keypecks or other possible patterns (Shimp, 1969, 1975; Shimp \& Hawkes, 1974).

\section{Results and Discussion}

Two preliminaries must be discussed before the principal results can be described. First, there is the question of the kind of baseline performance of leftkey runs that was established. Second, a decision must be made about the way in which a continuum of run lengths should be dichotomized into shorter and longer patterns.

For all practical purposes, the baseline performance in which a bird produced runs of left-key pecks duplicated the performance obtained earlier in experiments using the same or similar shaping procedures (Shimp, 1975, 1981, 1982, in press). Since no new shaping results were obtained, they need not be described fully here. Suffice it to say that the relative-frequency distributions of left-key run lengths showed the expected preponderance of run lengths near the reinforced values of 2 and 5 , with many cases not having any perceptible bimodality. Many curves were unimodal, with the mode near a run length of 2 and with relative frequencies of longer runs decreasing monotonically out to a run length of 5 (very few runs were longer than 5).

The dichotomization of such distributions into two categories, shorter and longer, poses difficult questions that, in principle, are unanswerable without a more elaborate theory than is now available: the chief difficulty is in deciding which runs to call short and which to call long. For example, does a run of length 3 belong to the shorter category surrounding reinforced runs of length 2 , does it belong to the longer category surrounding reinforced runs of length 5 , or does it belong to a third, ambiguous category? Fortunately, a rule of thumb has served admirably in the past. In earlier experiments involving shorter and longer reinforced patterns, it was found that analyses did not differ importantly when they were based exclusively upon responses in the two reinforced classes or upon, in addition, responses similar to these but outside the boundaries of rein- 
forced responses (Shimp, 1968, 1970). Thus, the rule has been to count a pattern as a shorter or longer one if it fell within the boundaries of the corresponding class of reinforced patterns. This rule was also applied here: we simply called a run a shorter one if it was of length 2 , and called a run a longer one if it was of length 5; all runs other than those of the lengths preceding probes were excluded from the following analyses. Since shorter and longer runs throughout the entire experiment were followed equally often by probes and, hence, ultimately by reinforcement, one would not expect preference for one over the other to have changed, and it did not: average preference for the shorter pattern, as measured by the number of shorter patterns divided by the number of shorter and longer patterns, remained within a range of approximately .72 to .82 throughout the experiment.

Over the conditions for which results are presented here, average reinforcements per hour ranged from 60 (Condition 4) to 164 (Condition 5).

Figure 1 shows the probability of a correct response in the side-key probes plotted against the retention interval. This probability is the number of pecks to a green key after a short pattern plus the number of pecks to a red key after a long pattern, divided by all side-key pecks (except for correction responses); only the first side-key peck in a probe was used. The averages of these numbers over the last 5 days of each condition are shown in Table 2.

Figure 1 shows these values for selected conditions: performance tended to improve with additional training, as is rather common in experiments with delayed matching-to-sample arrangements (see D'Amato, 1973, for a particularly striking example). On the basis of this gradual improvement, it was deemed advisable to have Figure 1 show only the results for the final condition when a retention interval was used in more than one condition. Group A was not exposed to a 6-sec retention interval because that group was already at a low level of performance at a retention interval of $2 \mathrm{sec}$. In general, a bird could report which pattern it had just produced with a rather high accuracy (average probability of a correct response was greater than .80 ) immediately after the termination of the pattern. (This probability presum-

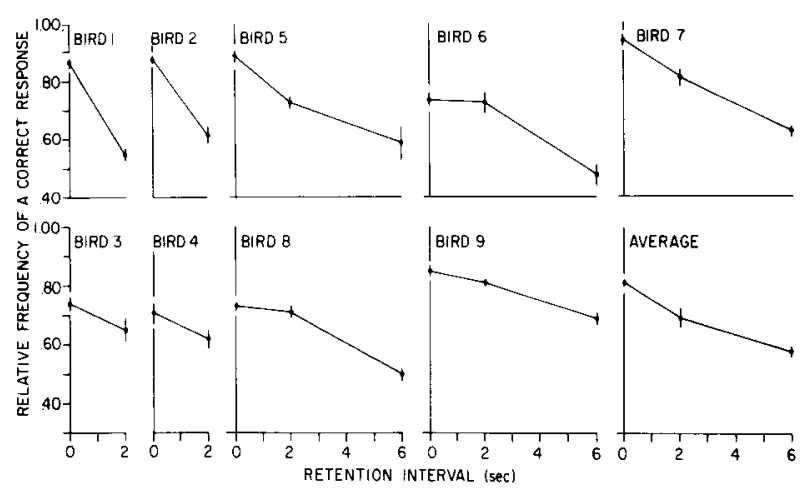

Figure 1. The relative frequency of a correct response as a function of the retention interval. Vertical lines represent plus and minus one standard error.

ably would have been somewhat higher still had not the procedure imposed a short delay equal to the latency to a center-key peck between the end of a pattern and the opportunity to report what pattern it was.) This ability to report the most recent pattern declined after only a few seconds to scarcely more than a chance level.

The behavioral patterning upon which reinforcement depended was shaped and maintained. As noted in the introduction, this behavioral adaptation to the run-length contingency can be said to indicate a kind of knowledge about the world similar to that displayed in most operant conditioning experiments. But, in addition, the behavior in the probes was a kind of self-commentary: it was a subject's description of its own adaptive behavior, which, as just noted, may be called its knowledge about the reinforcement contingency. Thus, the probe behavior may be interpreted as a form of metaknowledge, or an organism's knowledge about its own knowledge.

\section{EXPERIMENT 2}

Experiment 1 is a methodological extension of earlier work demonstrating metaknowledge in infrahumans. These earlier demonstrations, although using three different types of baseline behavior representing knowledge of reinforcement contingencies, have so far all used the same basic probe procedure to

Table 2

Probabllity (P) of a Correct Response and Standard Error (SE)

\begin{tabular}{|c|c|c|c|c|c|c|c|c|c|c|c|c|c|c|c|c|c|c|}
\hline \multirow{3}{*}{$\begin{array}{l}\text { Condi- } \\
\text { tion }\end{array}$} & \multicolumn{8}{|c|}{ Group A (Birds 1-4) } & \multicolumn{10}{|c|}{ Group B (Birds 5-9) } \\
\hline & \multicolumn{2}{|c|}{ Bird 1} & \multicolumn{2}{|c|}{ Bird 2} & \multicolumn{2}{|c|}{ Bird 3} & \multicolumn{2}{|c|}{ Bird 4} & \multicolumn{2}{|c|}{ Bird 5} & \multicolumn{2}{|c|}{ Bird 6} & \multicolumn{2}{|c|}{ Bird 7} & \multicolumn{2}{|c|}{ Bird 8} & \multicolumn{2}{|c|}{ Bird 9} \\
\hline & $\mathbf{P}$ & SE & $\mathbf{P}$ & SE & $\mathbf{P}$ & $\mathrm{SE}$ & $\mathbf{P}$ & SE & $\mathbf{P}$ & SE & $\mathbf{P}$ & SE & $\mathbf{P}$ & SE & $\mathbf{P}$ & SE & $\mathbf{P}$ & SE \\
\hline $\begin{array}{l}1 \\
2\end{array}$ & $\begin{array}{l}.83 \\
.55\end{array}$ & $\begin{array}{l}.02 \\
.02\end{array}$ & $\begin{array}{l}.71 \\
.62\end{array}$ & $\begin{array}{l}.03 \\
.02\end{array}$ & $\begin{array}{l}.75 \\
.65\end{array}$ & $\begin{array}{l}.04 \\
.04\end{array}$ & $\begin{array}{l}.61 \\
.62\end{array}$ & $\begin{array}{l}.04 \\
.03\end{array}$ & .68 & .05 & .73 & .05 & .89 & .02 & .54 & .03 & .86 & .01 \\
\hline $\begin{array}{l}3 \\
4 \\
5 \\
\end{array}$ & .87 & .01 & .87 & .01 & .74 & .02 & .71 & .03 & $\begin{array}{l}.73 \\
.59 \\
.89\end{array}$ & $\begin{array}{l}.02 \\
.06 \\
.02\end{array}$ & $\begin{array}{l}.73 \\
.48 \\
.74\end{array}$ & $\begin{array}{l}.04 \\
.04 \\
.02\end{array}$ & $\begin{array}{l}.81 \\
.63 \\
.94\end{array}$ & $\begin{array}{l}.03 \\
.02 \\
.02\end{array}$ & $\begin{array}{l}.71 \\
.50 \\
.73\end{array}$ & $\begin{array}{l}.02 \\
.02 \\
.01\end{array}$ & $\begin{array}{l}.81 \\
.69 \\
.85\end{array}$ & $\begin{array}{l}.01 \\
.02 \\
.02\end{array}$ \\
\hline
\end{tabular}


ask a subject what it knows about what it is doing. In humans, the picture one gets of a subject's metaknowledge and metamemory depends, in a highly sensitive manner, on precisely how one asks the subject what he or she knows or remembers about what he or she has done (Brown, 1975; Nisbett \& Wilson, 1977). Accordingly, to evaluate the generality of Experiment 1 and earlier work, Experiment 2 used a different probe technique, one that had proved to be remarkably efficient in animal short-termmemory experiments (Nelson \& Wasserman, 1978; Wasserman, Nelson, \& Larew, 1980).

\section{Method}

\section{Subjects}

Two White Carneaux pigeons were maintained according to the same procedures as described for Experiment 1. Bird 1 had served previously in a short-term-memory experiment involving sample stimuli consisting of food-hopper times, and Bird 2 had served previously in an experiment involving the reinforcement of various run lengths in a manner similar to the baseline contingency used here (Shimp, 1982, in press).

\section{Apparatus}

The apparatus was the same as that used in Experiment 1.

\section{Procedure}

Two different procedures were used. The procedure of Condition 2 was identical to that used in Experiment 1; the experimental parameters are shown in Table 3 . The other procedure had two parts, a pattern-shaping procedure and a probe procedure. The pattern-shaping procedure was identical to that of Experiment 1; the parameters are listed below. The probe procedure differed in important ways from that in Experiment 1 and is described below in detail.

Pattern-shaping procedure. This procedure had the same components as in Experiment 1.

Discrete-trials contingency. Throughout Experiment 2, the intertrial interval was $1.0 \mathrm{sec}$.

Variable-interval contingency. This was the same 2-sec VI as described for Experiment 1.

Response-pattern contingency. This was the same as for Experiment 1 .

Probe procedure. This component of the procedure was an alternative way of asking an organism what it remembered about the preceding pattern of behavior. As in Experiment 1, a keypeck initiated a retention interval if a random interval had timed out, if the keypeck was a changeover to the right key, and if it terminated the run length chosen by the response-pattern contingency. (No center-key peck was required to initiate the retention interval to position a bird near the middle of the chamber, since side keys were not used in Experiment 2.) A red or green center key appeared after the retention interval. A reinforcer was presented response-noncontingently at the end of a 5-sec centerkey presentation depending on the length of the previous pattern. The details were as follows.

Retention interval. Table 3 shows the value of the retention interval in each condition.

Test phase. When the retention interval timed out, red or green appeared on the center key, with the color varying randomly from one probe to another. Responding on the center key had no programmed consequences: it was always turned off after $5 \mathrm{sec}$. At its termination, reinforcement was delivered randomly on half of the probes: if the key had been green (red) and the most recent pattern a shorter (longer) one, reinforcement was delivered. Otherwise, no reinforcement was delivered, and the termination of the 5-sec center-key presentation immediately began an intertrial interval. There was no correction procedure of any kind arranged in the test phase of Experiment 2.

Experimental conditions. The conditions were designed primarily to permit an exploration of the effects of the retention interval with the autoshaping probe procedure. The two birds were also run, however, on the procedure of Experiment 1 in order to insure that their performances there were within the range of variability obtained in Experiment 1 . The procedure of Condition 2 was identical to that of Experiment 1, with the intertrial interval equal to $1.0 \mathrm{sec}$, the correction interval equal to $5.0 \mathrm{sec}$, and the retention interval equal to .1 sec. Experiment 2 began with the autoshaping probe procedure, switched to the probe procedure of Experiment 1, switched back to replicate Condition 1, and then ended with two conditions in which the retention interval was lengthened until performance was close to chance level.

\section{Miscellaneous Details}

Reinforcement was the same as in Experiment 1. Each session lasted $60 \mathrm{~min}$. As in Experiment 1, conditions were changed when it appeared that the number of obtained reinforcers, the distribution of run lengths, and the discrimination index (see Results below) were all reasonably stable. No numerical criterion of stability of any kind was used.

\section{Pretraining}

Pretraining consisted, first, of 89 days, during which left-key runs of lengths 2 and 5 were shaped, followed by the procedure of Experiment 1 for 13 days, at which time the level of performance in the side-key probes was at chance for both birds. They were then put on the autoshaping procedure as described above.

\section{Summary of the Procedure}

A pigeon pecked left and right keys in a discrete-trials setting and produced shorter and longer runs of left-key pecks as in Experiment 1. Occasionally, a changeover to the right key after a shorter or a longer run of left-key pecks was followed by a retention interval and then a 5 -sec red or green center key. The color of the center key, together with the preceding run, determined whether or not a reinforcer would be delivered: green after a shorter pattern and red after a longer pattern predicted reinforcement. It was expected that more autoshaped keypecking would occur to the green key after shorter patterns and to the red key after longer patterns.

\section{Results and Discussion}

The results for the autoshaping conditions are described in terms of a discrimination index equal to the number of pecks at a green center key after a shorter pattern plus the number of pecks at a red center key after a longer pattern, divided by the total number of pecks at a lighted center key. The mean and standard error of this number over the last 5 days of a condition are shown in Table 3. The results for Condition 2, which used the same procedure as was used in Experiment 1, were analyzed in the same manner as has been previously described for that experiment.

For a retention interval of $.1 \mathrm{sec}$, the discrimination index, averaged across both birds, was .61 in Condition 1 and .67 in the replication (Condition 3). For longer retention intervals, the index declined until it was not significantly above chance for either 
Table 3

Experimental Conditions and Results

\begin{tabular}{|c|c|c|c|c|c|c|}
\hline \multirow{2}{*}{$\begin{array}{l}\text { Condi- } \\
\text { tion }\end{array}$} & \multirow{2}{*}{$\begin{array}{l}\text { Number } \\
\text { of Days }\end{array}$} & \multirow[b]{2}{*}{$\mathrm{RI}$} & \multicolumn{2}{|c|}{ Bird 1} & \multicolumn{2}{|c|}{ Bird 2} \\
\hline & & & DI & SE & DI & $\mathrm{SE}$ \\
\hline 1 & 34 & .1 & .58 & .01 & .63 & .02 \\
\hline 2 & 15 & .1 & & & & \\
\hline 3 & 25 & .1 & .62 & .02 & .71 & .01 \\
\hline 4 & 15 & 2.0 & .52 & .01 & .60 & .01 \\
\hline 5 & 15 & 4.0 & .55 & .01 & .51 & .01 \\
\hline
\end{tabular}

Note $-R I=$ retention interval (in seconds); $D I=$ discrimination index; $S E=$ standard error. Preceding the 34 days in Condition 1 were 26 days during which the final duration of red and green center-key lights were selected. Preceding the 15 days in Condition 2 were 27 days during which different intertrial intervals were used (see text for discrimination indexes). A change in laboratory personnel, in particular in the animal handler, occurred on Day 10 of Condition 4 and appeared to produce erratic performance from Bird 2. The original handler therefore again took over the conduct of the experiment with the retention interval set back to .1 sec for 10 days, which were then followed by the 15 days described in the table.

bird at a retention interval of $4 \mathrm{sec}$. Thus, for this method, as with the method of Experiment 1, a bird could report what pattern it had most recently produced, and its ability to do so declined to approximately chance levels after a few seconds. That the present two birds' performances are representative is suggested by the results of Condition 2 , in which the probability and standard error of a correct response, .75 (.03) and .86 (.02) for Birds 1 and 2, respectively, are within the range of results obtained in Experiment 1.

\section{GENERAL DISCUSSION}

The baseline contingency operated as expected: shorter and longer temporal patterns were established in a manner resembling that on many previous occasions, both with the kinds of patterns used here, runs of successive choices (Shimp, 1982, in press), and with other kinds of patterns, such as interresponse times (Shimp, 1975) and interchangeover times (Shimp, 1979). By analogy with these earlier experiments (especially Shimp \& Hawkes, 1974), the present shorter and longer temporal patterns may be assumed to have been automatized, chunked, and unitized; they, not their component keypecks, may reasonably be assumed to have been analytical units (see Shimp, 1975, 1976, 1979, for a discussion of this point). This complex adaptation of the local temporal patterning of behavior can be said to represent a kind of knowledge about the reinforcement contingency: this behavioral adaptation is part of what would be referred to were one to say that an organism knows what behavior reinforcement depends on. Much of the molecular analysis of behavior consists in this sense in determining whether an organism can know whether reinforcement depends on various kinds of behavioral patterns, such as runs, interresponse times, interchangeover times, and so on.

The present experiment went beyond asking about this type of knowledge. It asked an additional question of whether an organism displaying knowledge of the behavior upon which' reinforcement is contingent can report what it is doing. The clear result was that, for a few seconds after producing a behavioral pattern, an organism can report what it has just done. Perhaps this kind of "self-report" is analogous to verbal self-reports by humans (Brown, 1975; Nisbett \& Wilson, 1977; Reber, 1967; Restle \& Brown, 1970).

The results from both Experiments 1 and 2 agree with the results of a previous experiment on metaknowledge in the pigeon in which the probe procedure was the same as that in the present Experiment 1 but the baseline performance consisted of a stream of shorter and longer interresponse times in a free-operant setting rather than a stream of shorter and longer runs of "choices" in a discrete-trials setting (Shimp, 1981). Thus, the present self-report methodology is applicable to at least two different kinds of behavioral patterns having temporal durations on the order of a few seconds, as well as to extremely brief response durations (Ziriax \& Silberberg, 1978). In addition, it is encouraging that two different kinds of probes, as in the present Experiments 1 and 2 , both permit obtaining self-reports of a pigeon's temporal patterning, since what may be roughly analogous self-reports by humans in various behavioral tasks prove delicately dependent upon the particular format of the self-reports (Nisbett \& Wilson, 1977).

The relation between knowledge and self-knowledge is one of the oldest problems in epistemology and philosophical pyschology. Views on this relation have moved from Descartes's position, "Nothing is easier for the mind to know than itself" (Rorty, 1979, p. 62 ), to the contemporary position that tends more to emphasize dissociations among various measures of knowledge and self-knowledge (Jacoby \& Dallas, 1981; Nisbett \& Wilson, 1977). The present experiments suggest that this problem, so often linked with verbal reports and conscious awareness in humans, can also be studied with organisms that are not only nonverbal, but also infrahuman. An interesting question for further research is, "How extensive and accurate a self-report of an acquired skill can an animal provide?"'

\section{REFERENCES}

Brown, A. L. The development of memory: Knowing, knowing about knowing, and knowing how to know. In $\mathrm{H}$. W. Reese (Ed.), Advances in child development and behavior (Vol. 10). New York: Academic Press, 1975. 
D'Aмaтo, M. R. Delayed matching and short-term memory in monkeys. In G. H. Bower (Ed.), The psychology of learning and motivation (Vol. 7). New York: Academic Press, 1973.

Gazzanica, M. S. The bisected brain. New York: AppletonCentury-Crofts, 1970.

Hawkes, L., \& Shimp, C. P. Choice between response rates. Journal of the Experimental Analysis of Behavior, 1974, 22, 109-115.

JACOBY, L. L., \& Dallas, M. On the relationship between autobiographical memory and perceptual learning. Journal of Experimental Psychology: General, 1981, 110, 306-340.

Nelson, T. D. Interresponse time as a stimulus: Discrimination and emission of interresponse time by pigeons. Unpublished doctoral dissertation, University of Maine, 1974.

Nelson, K. R., \& Wasserman, E. A. Temporal factors influencing the pigeon's successive matching-to-sample performance: Sample duration, intertrial interval, and retention interval. Journal of the Experimental Analysis of Behavior, 1978, 30, 153-162.

NisbetT, R. E., \& Wilson, T. D. Telling more than we can know: Verbal reports on mental processes. Psychological Review, 1977, 84, 231-259.

REBER, A. S. Implicit learning of artificial grammars. Journal of Verbal Learning and Verbal Behavior, 1967, 6, 855-863.

Restle, F., \& Brown, E. Organization of serial pattern learning. In G. H. Bower (Ed.), Psychology of learning and motivation (Vol. 4). New York: Academic Press, 1970.

RoRTy, T. Philosophy and the mirror of nature. Princeton, N.J: Princeton University Press, 1979.

Shimp, C. P. Probabilistically reinforced choice behavior in pigeons. Journal of the Experimental Analysis of Behavior, 1966, 9, 443-455.

ShIMP, C. P. Magnitude and frequency of reinforcement and frequencies of interresponse times. Journal of the Experimental Analysis of Behavior, 1968, 11, 525-535.

Shimp, C. P. The concurrent reinforcement of two interresponse times: The relative frequency of an interresponse time equals its relative harmonic length. Journal of the Experimental Analysis of Behavior, 1969, 12, 403-411.

Shimp, C. P. The concurrent reinforcement of two interresponse times: Absolute rate of reinforcement. Journal of the Experimental Analysis of Behavior, 1970, 13, 1-8.

Shimp, C. P. Perspectives on the behavioral unit: Choice behavior in animals. In W. K. Estes (Ed.), Handbook of learning and cognitive processes (Vol. 2). Hillsdale, N.J: Erlbaum, 1975.

Shimp, C. P. Organization in memory and behavior. Journal of the Experimental Analysis of Behavior, 1976, 26, 113-130.

Shimp, C. P. The local organization of behavior: Method and theory. In M. D. Zeiler \& P. Harzem (Eds.), Advances in analysis of behavior (Vol. 1): Reinforcement and the organization of behavior. Chichester, England: Wiley, 1979.

Shimp, C. P. The local organization of behavior: Discrimination of and memory for simple behavioral patterns. Journal of the Experimental Analysis of Behavior, 1981, 36, 303-315.

Shimp, C. P. Choice and behavioral patterning. Journal of the Experimental Analysis of Behavior, 1982, 37, 157-169.

ShImp, C. P. Reinforcement and the local organization of behavior. In M. L. Commons, R. J. Herrnstein, \& H. Rachlin (Eds.), Quantitative analyses of behavior (Vol. 2): Matching and maximizing accounts. Cambridge, Mass: Ballinger, in press.

Shimp, C. P., \& Hawkes, L. Time-allocation, matching and contrast. Journal of the Experimental Analysis of Behavior, 1974, 22, 1-10.

Wasserman, E. A., Nelson, K. R., \& Lahew, M. B. Memory for sequences of stimuli and responses. Journal of the Experi. mental Analysis of Behavior, 1980, 34, 49-59.

Ziriax, J. M., \& Silberberg, A. Discrimination and emission of different key-peck durations in the pigeon. Journal of Experimental Psychology: Animal Behavior Processes, 1978, 4, $1-21$.

(Manuscript received October 8, 1981; revision accepted for publication March 9, 1982.) 